$\begin{array}{ccc}\text { Gazi University } & \text { Journal of Science } \\ \text { http://dergipark.gov.tr/gujs } & \text { (ged }\end{array}$

\title{
Novel Technique to Measure Moisture Content of Paddy and the Error Correction
}

\author{
Divya NATHK ${ }^{10}$, Prabhu RAMANATHAN ${ }^{1, *}$ \\ ${ }^{I}$ School of Electrical Engineering, Vellore Institute of Technology, Vellore, India
}

\author{
Highlights \\ - Large quantity of samples can be used to measure moisture content at a time. \\ - The moisture meter was developed by designing an integrated circuit and it is interfaced with PC. \\ - The parallel plate sensor technique used to measure the capacitance is highly accurate. \\ - The error was corrected using Matlab program.
}

Article Info

Received: 06/03/2018

Accepted: $22 / 03 / 2019$

\section{Keywords}

Moisture content measurement Non-destructive method Parallel plate capacitor Error correction Relative permittivity

\begin{abstract}
The moisture content in agricultural products is very critical. The presence of moisture also affects the quality of agricultural products like rice, wheat, nuts etc. Moisture content in food grains should be reduced and made optimum value otherwise it would encourage fungi development. The development of fungus makes the grain useless. For measuring the capacitance of paddy grains, designed integrated circuit was interfaced with the PC. The arrangement used is a high precision impedance converter. It is a 12 bit frequency generator and 1 Mega samples / sec analog to digital converter. Frequency sweep can be done using the circuit. This converter is interfaced with PC to measure the capacitance of paddy. Initially ceramic capacitors of different values were used to check the designed circuit. Then using the designed circuit, capacitance of representative amount of samples was measured and calculated the moisture content from the obtained readings. The technique is fast, simple, accurate and non-destructive method. Though the method is accurate, there is a slight variation in decimal points and the error was also corrected using Matlab.
\end{abstract}

\section{INTRODUCTION}

In India, agriculture is a main source of income. For storage of agricultural products like paddy, wheat and nuts the moisture content (MC) is a factor, critical to its shelf life. The MC in food grains should be known by the farmers for their processing, trading and storage, else fungi affect the grains. The affected grains become unusable [1,2]. During the time of harvesting, the water content in grains will be approximately $20 \%-40 \%$, which has to be reduced to $10 \%-13 \%$ for storing, processing and trading [3].

The direct or indirect method can be used to measure the MC. In direct technique MC is calculated using the equation (1)

Dry basis \% MC $=\frac{\text { (Wet weight of sample }- \text { Dry weight of Sample) }}{\text { Dry weight of sample }}$.

Time consumption and complexity are more for the direct process, as the water content of samples has to be removed completely to find the weight of dry samples. In the indirect technique any of the physical property having relation with moisture is measured and moisture content is calculated. For example the resistance of the grain as a physical property which has the relation with moisture, the moisture content will be less as the resistance increases. 
In the beginning of $20^{\text {th }}$ century capacitive type moisture meters were used to measure moisture. Later the electrical grain moisture meters were developed $[4,5,6]$. In electric resistance method when current is passed through the samples (soil \& wheat) whose MC have to be measured, samples got cracked and were wasted. The advantage of this technique was its low cost $[7,8,9,10,11]$. With the concept of dielectric property, grain moisture meter was developed. Rice and barley were the samples tested. At high frequency calibration variation happens due to ionic conduction and in low frequency variation in calibration is not accountable. So microwave signals with moisture density and attenuation at $10.5 \mathrm{GHz}$ was used to measure the MC [9]. The double capacitor cell with immersion method as the principle, the dielectric constant of twelve grains like rice, soybean, wheat, linseed, paddy, mustard in the frequency range $200 \mathrm{~Hz}$ to $2 \mathrm{KHz}$ were measured [12]. The electrical spectroscopy was used to measure the MC of tea leaves. The capacitance and impedance were measured for the range of frequency from $10 \mathrm{~Hz}$ to $1 \mathrm{MHz}$ [13]. By measuring the magnetic strength produced by samples, MC was measured [14]. It is clear that at any designed frequency the MC can be obtained accurately. The main disadvantage was that only few quantities of samples were used at a time to measure moisture content. MC was measured for different types of wheat, nuts, grains, inshell peanut, wood chips, dry cherries by Chari V Kandala. Initially RF impedance method was used to measure the MC $[3,15]$. Later he developed CI (Chari Impedance) meter and calculated impedance and phase angle from the observed values $\mathrm{e}_{\mathrm{m} 1}, \mathrm{e}_{\mathrm{r} 1}$, and $\mathrm{e}_{\mathrm{p} 1}$ where $\mathrm{e}_{\mathrm{r} 1}$ is the actual input voltage, $\mathrm{e}_{\mathrm{m} 1}$ is the output voltage after passing through samples, $\mathrm{e}_{\mathrm{p} 1}$ is the output voltage of phase detector. The impedance and phase angle were substituted in empirical formula and MC was calculated [1, 2, 3, 16, 17, 18, 19]. With slightly modified empirical formula, oil content in peanut kernels was also measured using same experiment at different frequencies and compared with Soxhlet result [20]. By using electrical or magnetic properties of food grains many indirect and non-destructive techniques for measuring $\mathrm{MC}$ have been developed over last few decades. Most of the techniques developed to calculate the content of moisture were complex, time consuming and could be used only for few grams as samples.

In this paper a novel technique has been used to measure the moisture content. The moisture meter was developed by designing an integrated circuit and it is interfaced with PC. The capacitance of paddy was measured using the circuit which helped to calculate dielectric constant of the grains. Larger the value of relative permittivity, the MC is more but the increase is not uniform for all the food commodities [21]. Since this method is a non-destructive technique, no labour is required to clean and crush. The method developed is very simple to measure the MC, requires less time and it is very economic. Large quantity of samples can be used to measure moisture content at a time. The comparative study of all the above method is also analysed [22, 23, 24].

\section{METHODOLOGY}

\subsection{Calibration and Testing}

Moisture meter is an impedance converter made of evaluation board of AD 5933 with voltage follower and non inverting amplifier in which frequency sweep can be done efficiently. The evaluation board is interfaced with PC. Initially, calibration of the meter was done with feedback resistor and calculated resistor which are obtained using (2) and (3)

$$
\begin{gathered}
R_{f b}=\frac{\left.\frac{\left(V_{D D}\right.}{2}-0.2\right) Z_{\text {min }}}{V_{p k}+\frac{V_{D D}}{2}-V_{D C \text { offset }}} \times \frac{1}{\text { gain }} \\
V_{D D}=3.2 \mathrm{~V} \text { and } V_{P K}=V_{p-p}=1 \mathrm{~V} .
\end{gathered}
$$

$\mathrm{V}_{\mathrm{DD}}$ is the biasing voltage and $\mathrm{V}_{\mathrm{PK}}$ is the peak voltage

Setting of $V_{P-P}$ and gain is done in the display screen of user interface.

$$
R_{f b}=82893.34 \Omega \approx 10 \mathrm{~K} \Omega
$$

$R_{\text {cal }}=\frac{Z_{\max }+Z_{\min }}{3}$ 
$R_{\text {cal }}=906298.9667 \Omega \approx 1 \mathrm{M} \Omega$.

The maximum range of impedance, $Z_{\max }$ or maximum reactance is calculated for the capacitor value of 2 $\mathrm{pF}$. The minimum range of impedance, $\mathrm{Z}_{\min }$ or minimum reactance is for capacitor value of $100 \mathrm{pF}$. Assuming capacitance can be varied from 2 to $80 \mathrm{pF}$. For the values of resistors $\mathrm{R}_{\mathrm{fb}}$ and $\mathrm{R}_{\mathrm{cal}}$ the frequency sweep can be done from $30 \mathrm{KHz}$ to $1 \mathrm{MHz}$. The block diagram and the circuit diagram of the moisture meter are shown in Figure 1(a) and Figure 1(b) respectively. It was used to measure the ceramic capacitors of value $10 \mathrm{pF}, 22 \mathrm{pF}, 27 \mathrm{pF}, 47 \mathrm{pF}$ and $3.9 \mathrm{pF}$ and few set of readings are tabulated in Table 1 . The voltage divider resistors, $\mathrm{R}=50 \mathrm{~K} \Omega, \mathrm{R}_{1}=20 \mathrm{~K} \Omega$ and capacitor, $\mathrm{C}=47 \mathrm{nF}$. The operational amplifier used is CMOS.

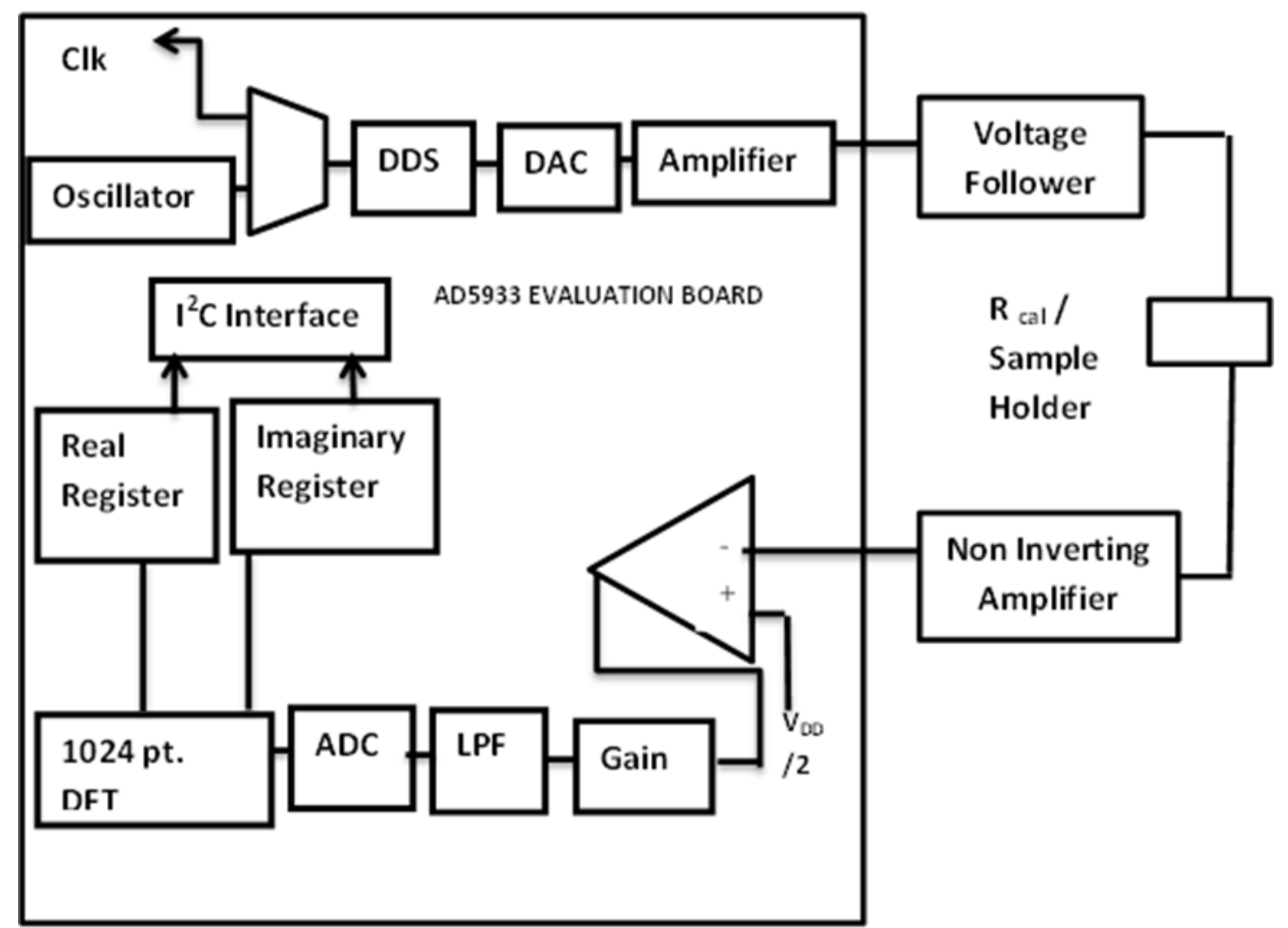

Figure 1(a). Block Diagram to Measure the Capacitor Value

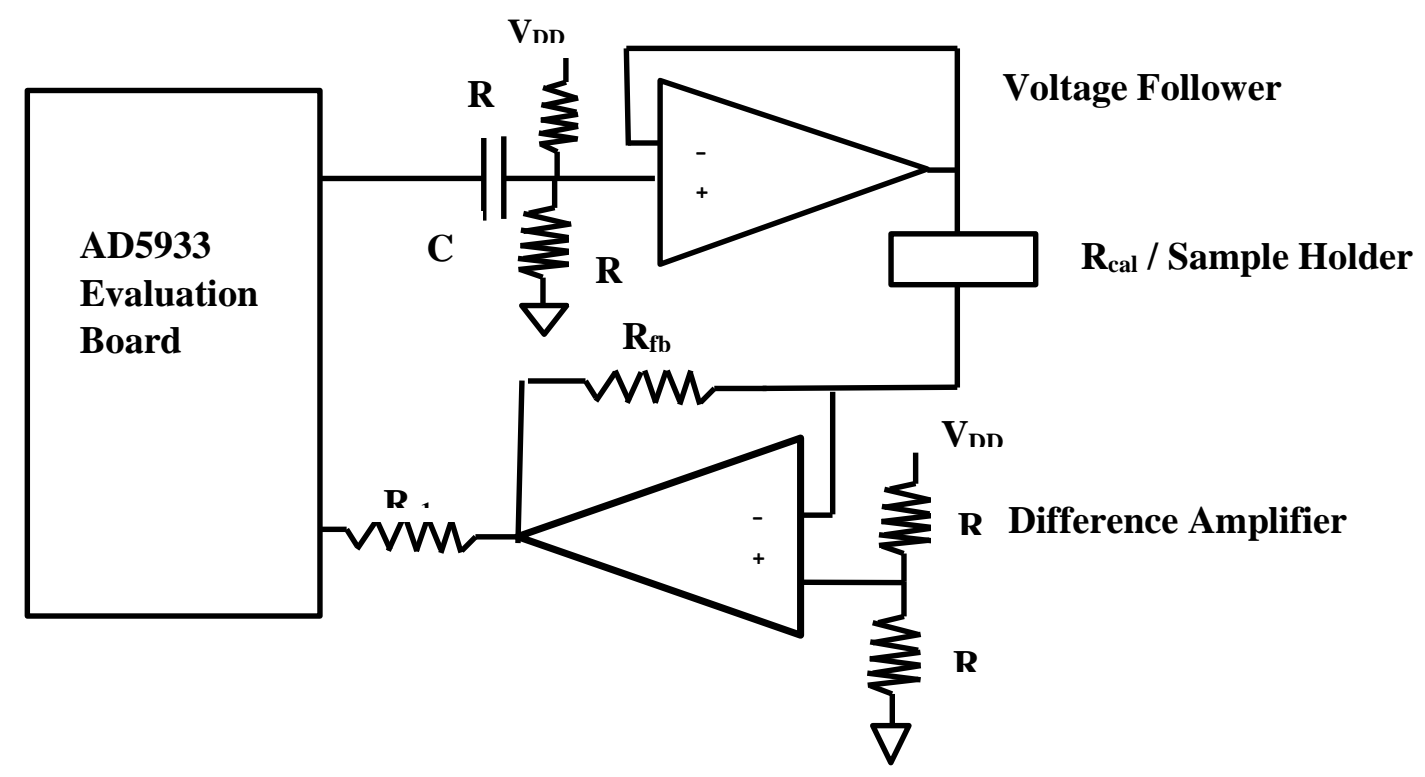

Figure 1(b). Circuit Diagram to Measure the Capacitor Value 
The reading shows that the degree of accuracy of the moisture meter is high and can be used to measure the capacitance of paddy. Here the frequencies swept were from $30 \mathrm{KHz}$ to $50 \mathrm{KHz}$ and the impedances were measured and noted ten set of such readings. From the value of impedance, capacitor values were calculated using the equation (4) or (5)

$X_{C}=\frac{1}{2 \pi \mathrm{fC}}$

or $C=\frac{1}{2 \pi f X_{c}}$.

All the value indicates that moisture meter has high degree of accuracy. The readings were taken and graphs were plotted for different frequencies versus different ceramic capacitor values and are shown in Figure 2. The graph clearly indicates that capacitor value remains constant for different frequencies. The meter is efficient for a frequency range $30 \mathrm{KHz}$ to $50 \mathrm{KHz}$. The moisture meter can be used to measure the capacitance of paddy or any food grains.

Table 1. Readings of Different Ceramic Capacitor Values

\begin{tabular}{|l|l|l|l|l|l|l|l|l|}
\hline \multirow{2}{*}{$\begin{array}{l}\text { Frequ } \\
\text { ency } \\
(\mathrm{KHz})\end{array}$} & \multicolumn{2}{|l|}{$\begin{array}{l}\text { Actual Ceramic } \\
\text { Capacitor of } 10 \mathrm{pF}\end{array}$} & \multicolumn{2}{|l|}{$\begin{array}{l}\text { Actual Ceramic } \\
\text { Capacitor of } 22 \mathrm{pF}\end{array}$} & \multicolumn{2}{l|}{$\begin{array}{l}\text { Actual Ceramic } \\
\text { Capacitor of } 27 \mathrm{pF}\end{array}$} & \multicolumn{2}{l|}{$\begin{array}{l}\text { Actual Ceramic } \\
\text { Capacitor of } 47 \mathrm{pF}\end{array}$} \\
\cline { 2 - 9 } & $\begin{array}{l}\text { Impedance } \\
(\Omega)\end{array}$ & $\begin{array}{l}\text { Obtained } \\
\text { Capacitor } \\
\text { Value } \\
(\mathrm{pF})\end{array}$ & $\begin{array}{l}\text { Impedance } \\
(\Omega)\end{array}$ & $\begin{array}{l}\text { Obtained } \\
\text { Capacitor } \\
\text { Value } \\
(\mathrm{pF})\end{array}$ & $\begin{array}{l}\text { Impedanc } \\
\mathrm{e}(\Omega)\end{array}$ & $\begin{array}{l}\text { Obtained } \\
\text { Capacitor } \\
\text { Value } \\
(\mathrm{pF})\end{array}$ & $\begin{array}{l}\text { Impedance } \\
(\Omega)\end{array}$ & $\begin{array}{l}\text { Obtained } \\
\text { Capacitor } \\
\text { Value } \\
(\mathrm{pF})\end{array}$ \\
\hline 12 & 510370.7 & 9.78 & 241341.1 & 22 & 294536.2 & 27.032 & 251795.8 & 52.70 \\
\hline 33 & 463973.4 & 9.95 & 241192.8 & 22 & 235947.5 & 26.995 & 91043.8 & 53.00 \\
\hline 34 & 446038.3 & 9.61 & 240981.2 & 22 & 196160.1 & 27.059 & 88199.7 & 53.10 \\
\hline 38 & 399086.9 & 9.92 & 240619.8 & 22.1 & 184228.2 & 27.011 & 79213.8 & 52.90 \\
\hline 39 & 392592.9 & 983 & 241126.1 & 22 & 178519.9 & 27.030 & 77328.9 & 52.8 \\
\hline 40 & 382778.1 & 9.89 & 240768.6 & 22 & 168341.2 & 27.026 & 75395.7 & 52.8 \\
\hline 41 & 369885.4 & 9.74 & 241555.2 & 22 & 146917.5 & 27.096 & 73556.8 & 52.8 \\
\hline 48 & 318981.7 & 9.77 & 241768.3 & 21.9 & 130946.1 & 27.023 & 62829.7 & 52.8 \\
\hline 49 & 312471.9 & 9.83 & 242711 & 21.9 & 120547.5 & 26.958 & 61664.3 & 52.7 \\
\hline 50 & 306222.4 & 9.72 & 240981.2 & 22 & 117846.3 & 27.024 & 60088.9 & 53 \\
\hline
\end{tabular}




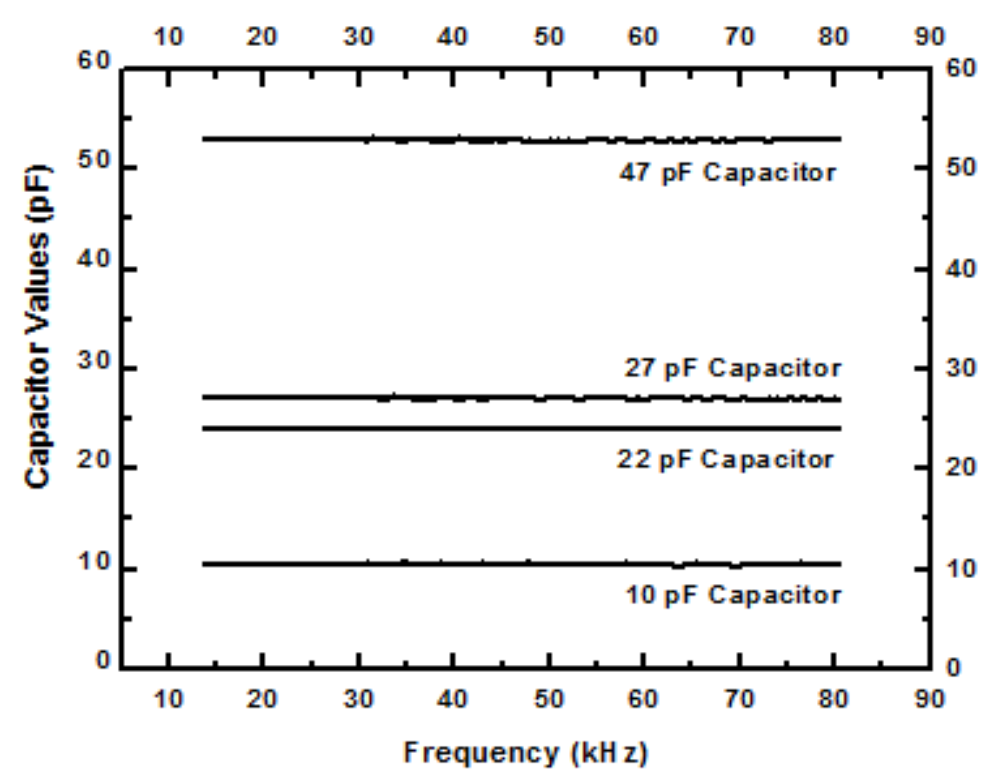

Figure 2. The graph between different ceramic capacitor value and frequency

\subsection{Parallel Plate Sensor}

To measure the MC of paddy, sample holder is required to place the samples. The parallel plate sensor technique used to measure the capacitance is highly accurate. A rectangular glass tube of wall-thickness 5 $\mathrm{cm}$ is used as holder for the sample. The rectangular face is of the size $10.8 \mathrm{~cm}$ long and $15.8 \mathrm{~cm}$ wide. The base of the rectangular glass tube is of the size $5 \mathrm{~cm} \times 15.8 \mathrm{~cm}$. The two parallel plates rectangular electrodes of the size $10.8 \mathrm{~cm}$ long and $15.8 \mathrm{~cm}$ wide are placed internally on the faces of the rectangular box and it forms the two sides of parallel plate sensor. The distance between two parallel plate electrodes is $5 \mathrm{~cm}$. The parallel plate sensor is shown in Figure 3. The two electrodes which are opposite faces of the parallel plate container are blue in colour and capacitance was calculated using the formula (6).

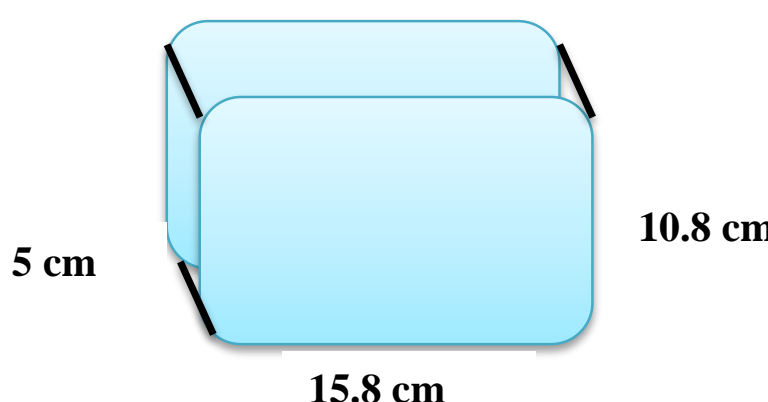

Figure 3. Parallel plate Sensor

$$
C=\frac{\varepsilon_{0} \varepsilon_{\mathrm{r} 1} \mathrm{~A}}{\mathrm{~d}}=\frac{8.854 \times 10^{-12} \times 1 \times 0.108 \times 0.158}{0.05}=3.022 \mathrm{pF}
$$

The capacitance of parallel plate sensor was also measured using the moisture meter and readings are tabulated in Table 2. 


\section{SAMPLE PREPARATION}

Paddy being the most important crop in Kerala, India the samples used is paddy of different moisture content collected from the Palakkad district, Kerala. Paddy of three different moisture contents were considered as samples - sun dried paddy, moist paddy and oven dried paddy. The arrangement to measure the impedance consists of a PC for interfacing, evaluation board, bread broad where the calibration elements are placed and the parallel plate sensor to place the paddy. The arrangement is shown in Figure 4.

\subsection{Sun Dried Paddy}

After harvesting the paddy from field, it was placed on direct sun for four hours from morning 10 am to 2 $\mathrm{pm}$ at atmospheric temperature of $29^{\circ} \mathrm{C}$. This sun dried paddy was placed in parallel plate sensor and the impedance was measured using the arrangement as in Figure 4. Weight was measured using the weighing machine and found to be 323.5 grams. The impedance of oven dried paddy is tabulated in Table 2 .

\subsection{Moist Paddy}

Impedance value of fresh harvested paddy without drying was measured using the same arrangement and readings obtained during the experiment are tabulated in Table 2 . The readings indicate that capacitor value is increasing with increase in moisture. The weight of moist paddy was also noted and it was 350 grams.

\subsection{Oven Dried Paddy}

The paddy sample was heated in micro oven for 30 minutes at $180{ }^{\circ} \mathrm{C}$ and removed the complete moisture. The impedance of oven dried paddy sample was measured using the same arrangement as in Figure 4 . The weight of oven dried paddy was 299 grams. The readings shows that MC is less as capacitor value obtained is less compared to sun dried and fresh paddy. The readings obtained when the sun dried paddy was placed in the sample holder are in Table 2.

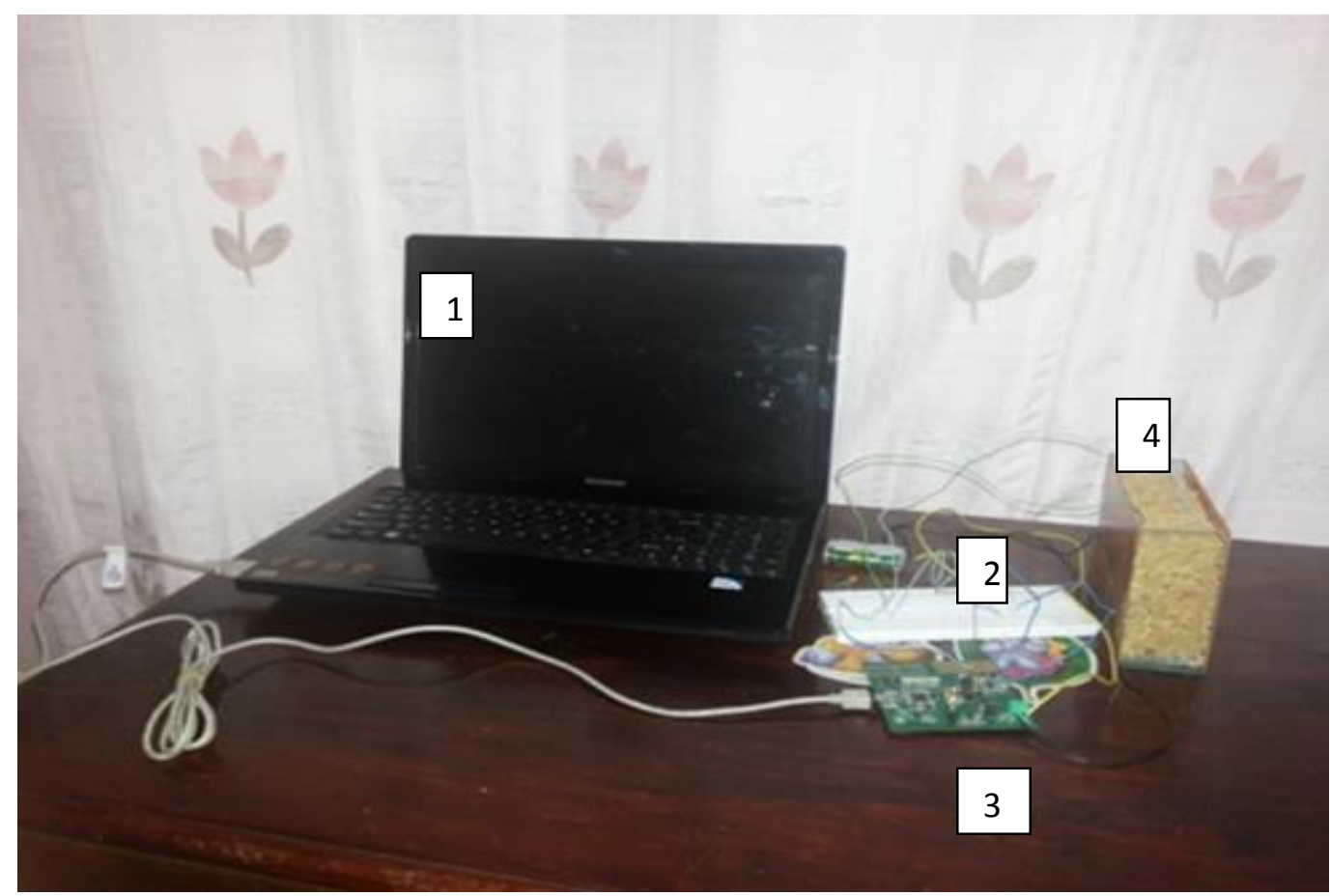

Figure 4. The Arrangement to Measure the MC of Paddy. 1. Personal Computer 2. Bread-Board 3. Evaluation Board 4. Parallel Plate Sensor 
Table 2. Variation of Capacitive Value of Different Moisture Content Paddy with Frequency.

\begin{tabular}{|l|l|l|l|l|l|l|l|l|}
\hline $\begin{array}{l}\text { Frequ } \\
\text { ency } \\
(\mathrm{KHz})\end{array}$ & $\begin{array}{l}\text { Impedance } \\
(\Omega)\end{array}$ & $\begin{array}{l}\text { Empty } \\
\text { paralle } \\
\text { 1 plate } \\
\text { sensor } \\
(\mathrm{pF})\end{array}$ & $\begin{array}{l}\text { Impedance } \\
(\Omega)\end{array}$ & $\begin{array}{l}\text { Moist } \\
\text { Paddy } \\
(\mathrm{pF})\end{array}$ & $\begin{array}{l}\text { Impedance } \\
(\Omega)\end{array}$ & $\begin{array}{l}\text { Sun } \\
\text { dried } \\
\text { Paddy } \\
(\mathrm{pF})\end{array}$ & $\begin{array}{l}\text { Impedance } \\
(\Omega)\end{array}$ & $\begin{array}{l}\text { Oven } \\
\text { heated } \\
\text { Paddy } \\
(\mathrm{pF})\end{array}$ \\
\hline 31.2 & 1551278.825 & 3.29 & 215346.301 & 23.7 & 245370.545 & 20.8 & 344845.090 & 14.8 \\
\hline 31.3 & 1546322.662 & 3.31 & 214658.2936 & 23.7 & 245768.191 & 20.7 & 341436.346 & 14.9 \\
\hline 32.7 & 1480119.246 & 3.23 & 204604.7192 & 23.8 & 235246.006 & 20.7 & 256294.333 & 19 \\
\hline 35.5 & 1363377.446 & 3.21 & 188466.8822 & 23.8 & 218805.454 & 20.5 & 301041.060 & 14.9 \\
\hline 35.9 & 1348186.611 & 3.19 & 185587.1945 & 23.9 & 216367.510 & 20.5 & 295702.263 & 15 \\
\hline 36 & 1344441.648 & 3.15 & 186633.4608 & 23.7 & 214719.079 & 20.6 & 296859.934 & 14.9 \\
\hline 38 & 1273681.561 & 3.28 & 175331.0601 & 23.9 & 201462.132 & 20.8 & 291000.857 & 14.4 \\
\hline 31.2 & 1551278.825 & 3.29 & 215346.301 & 23.7 & 245370.545 & 20.8 & 344845.090 & 14.8 \\
\hline 31.3 & 1546322.662 & 3.31 & 214658.2936 & 23.7 & 245768.191 & 20.7 & 341436.346 & 14.9 \\
\hline 32.7 & 1480119.246 & 3.23 & 204604.7192 & 23.8 & 235246.006 & 20.7 & 256294.333 & 19 \\
\hline
\end{tabular}

The capacitance of empty parallel plate sensor, moist paddy, sun dried paddy and oven heated paddy are calculated using the equation (5)

\section{RESULTS}

The circuit was tested by measuring the capacitance of different ceramic capacitors. The readings obtained are tabulated in Table 1 and graph of ceramic capacitors are shown in Figure 1 which shows the values of ceramic capacitors remain constant. Table 2 shows the capacitance values of paddy samples with different MC. The result obtained by conducting the experiment shows that the capacitance value is larger for the paddy having more moisture content. The variation of capacitor value of different paddy samples with frequency is as shown in Figure 5. The capacitance of paddy having different moisture content remains constant.

The dielectric constant of sun dried paddy, moist paddy and oven dried paddy can be calculated. The ideal value of relative permittivity and capacitance of parallel plate sensor without samples is, $\varepsilon_{\mathrm{r} 1}=1$ and $\mathrm{C}_{1}=$ $3.28 \mathrm{pF}$. 


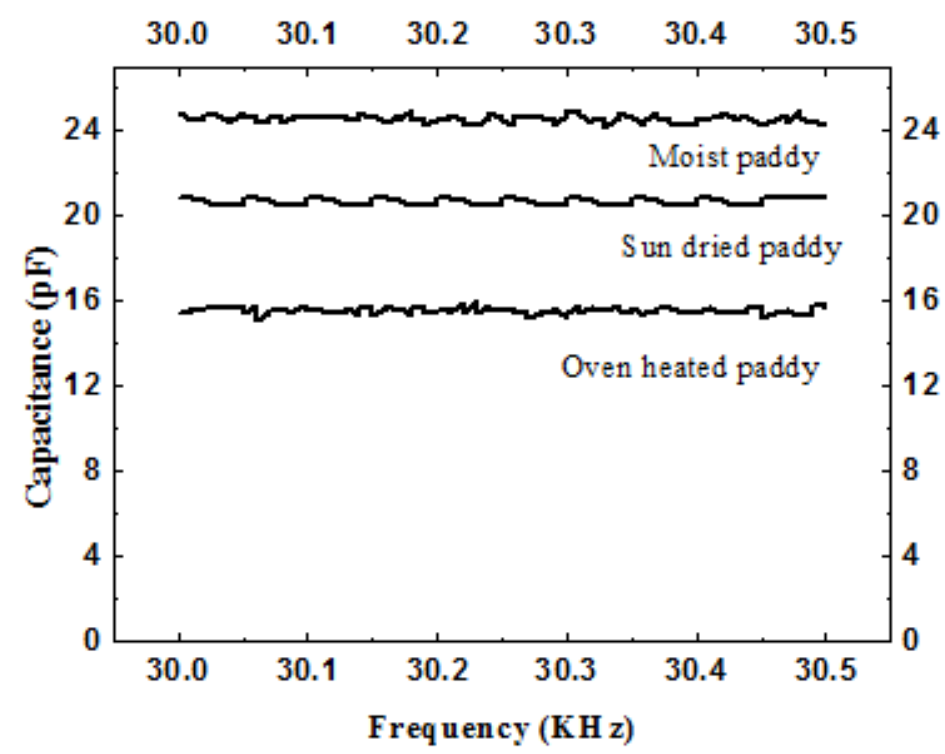

Figure 5. Variation of Capacitor Value for Different Paddy Samples

Let $\mathrm{C}_{2}$ be the capacitance of sun dried paddy then $\varepsilon_{\mathrm{r} 2}$ can be obtained by dividing equation (7) by $\left(\mathrm{C}_{1}\right)$ or by empty parallel plate sensor.

$C_{2}=\frac{\varepsilon_{0} \varepsilon_{\mathrm{r} 2} \mathrm{~A}}{\mathrm{~d}}$

$$
\begin{gathered}
\frac{C_{2}}{C_{1}}=\frac{\varepsilon_{r 2}}{\varepsilon_{r 1}}=\frac{20.8}{3.28} \\
\varepsilon_{\mathrm{r} 2}=6.34
\end{gathered}
$$

Similarly the relative permittivity of moist paddy and oven dried paddy can be calculated. Let $C_{3}, \varepsilon_{\mathrm{r} 3}$ and $C_{4}, \varepsilon_{\mathrm{r} 4}$ be the capacitance and relative permittivity of moist paddy and oven dried paddy respectively then $\varepsilon_{\mathrm{r} 3}=7.256$ and $\varepsilon_{\mathrm{r} 4}=4.8$. The relative permittivity is less for oven dried samples of paddy and it is maximum for moist paddy. The Figure 6 shows the variation of relative permittivity for different moisture content paddy. The relative permittivity is increasing with increase in the MC. The promising result is obtained from the test. The quantity of samples used in the moisture meter can be more and time taken to measure the $\mathrm{MC}$ is just few seconds.

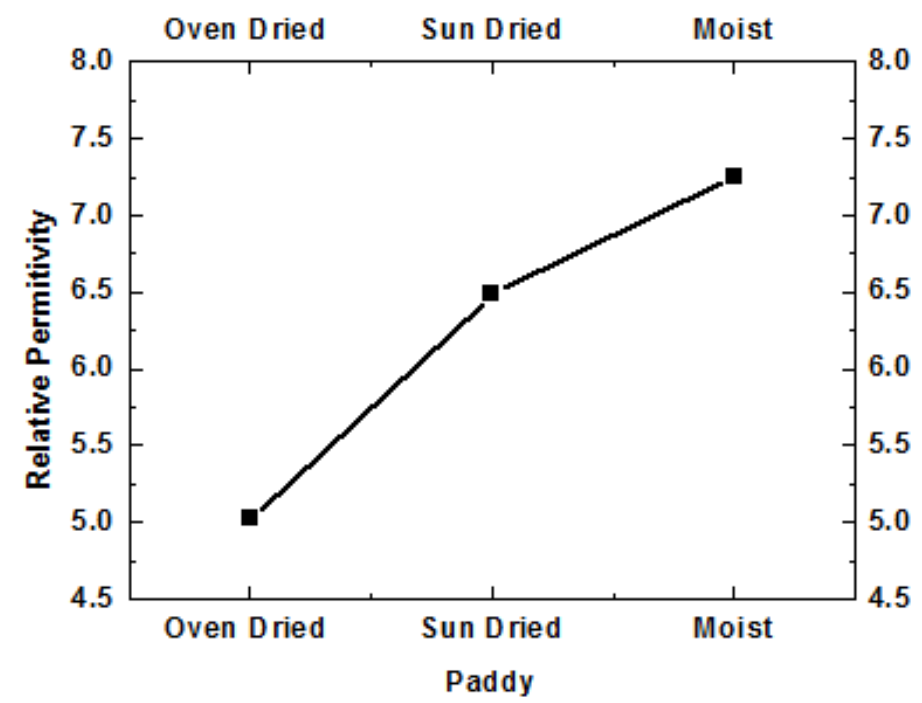

Figure 6. Variation of Relative Permittivity for Different Moisture Content Paddy Samples 
The $\%$ MC of moist paddy and sun dried paddy were calculated using the formula (8) and tabulated in Table 3. The safe amount of $\% \mathrm{MC}$ is $10 \%$ to $13 \%$. In sun dried paddy $\% \mathrm{MC}$ is less comparing to moist paddy, but for safe storage it should be dried again and the water content has to be reduced.

$\% \mathrm{MC}=\frac{\text { (Capacitive value of wet sample }- \text { Capacitive value of dry Sample) }}{\text { Capacitive value of wet sample }}$

Table 3. Variation of $\%$ MC with Oven Heated Values

\begin{tabular}{|l|l|l|}
\hline $\begin{array}{l}\text { \% MC in Moist } \\
\text { paddy }\end{array}$ & $\begin{array}{l}\text { \% MC in Sun } \\
\text { dried paddy }\end{array}$ & $\begin{array}{l}\text { Oven heated } \\
\text { Paddy }\end{array}$ \\
\hline 38.24 & 29.33 & 14.7 \\
\hline 37.55 & 28.85 & 14.8 \\
\hline 37.13 & 28.02 & 14.9 \\
\hline 37.17 & 27.54 & 14 \\
\hline 37.39 & 27.32 & 14.9 \\
\hline 37.24 & 26.83 & 15 \\
\hline 37.13 & 27.67 & 14.9 \\
\hline 39.75 & 27.77 & 14.4 \\
\hline
\end{tabular}

\section{ERROR CORRECTION}

A set of hundred readings are obtained using the circuit shown in Figure 1(b) and it is plotted. The graph of $10 \mathrm{pF}$ is and its corrected data are shown in Figure 7 (a). The error was corrected using Matlab program. Similarly for $22 \mathrm{pF}, 27 \mathrm{pF}, 47 \mathrm{pF}$, moist paddy, sun dried paddy and oven heated paddy error correction were also done and plotted. The graphs are shown in Figure 7 (b), Figure 7 (c), Figure 7 (d), Figure 7 (e), Figure 7 (f), and Figure 7 (g).

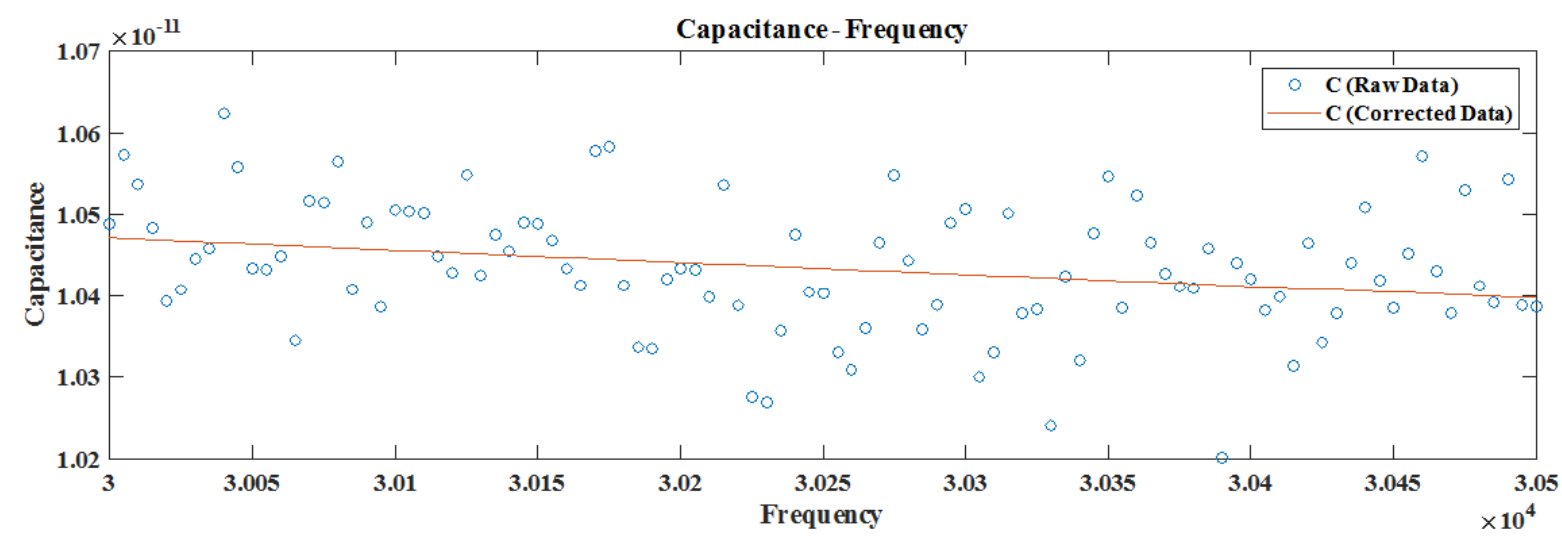

Figure 7 (a). Graph of 10 pF Capacitor 


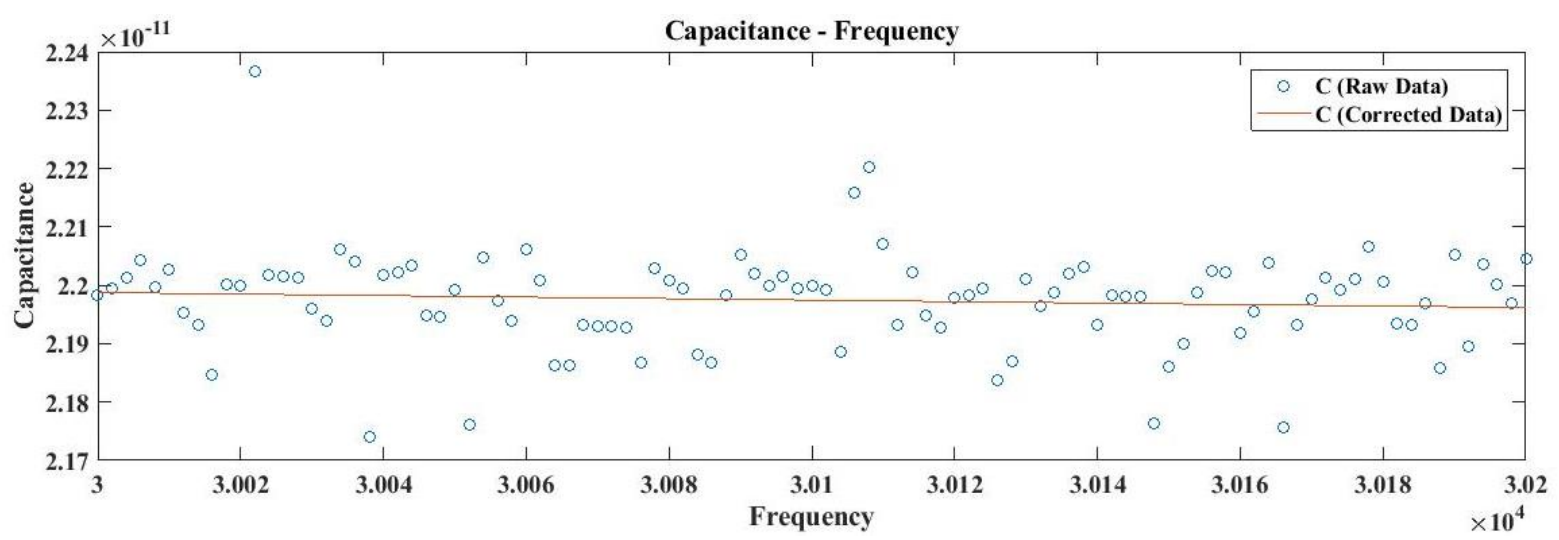

Figure 7 (b). Graph of 22 pF Capacitor

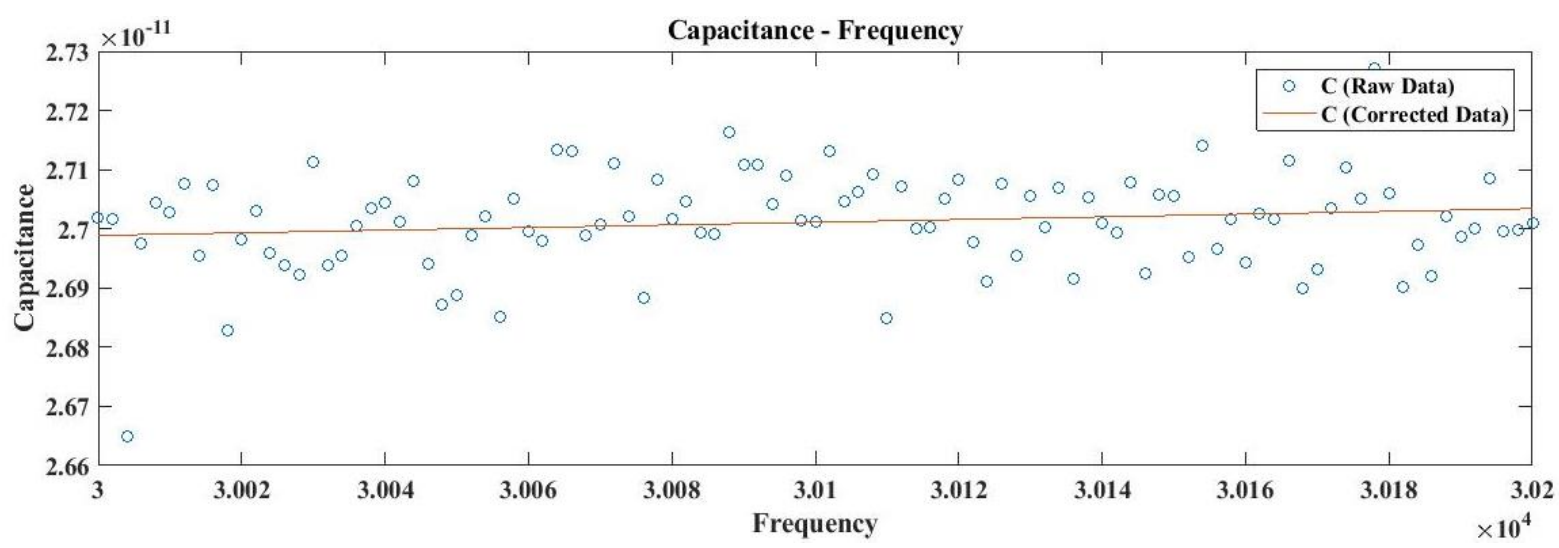

Figure 7 (c). Graph of 27 pF Capacitor

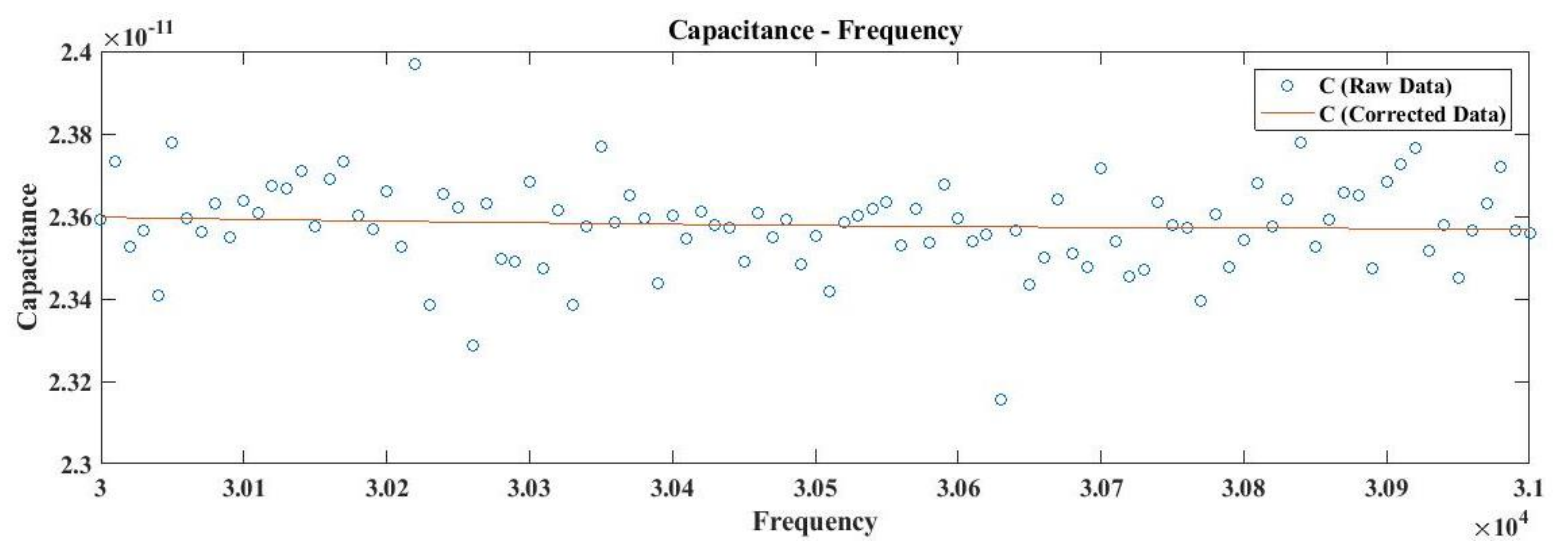

Figure 7 (d). Graph of Moist Paddy

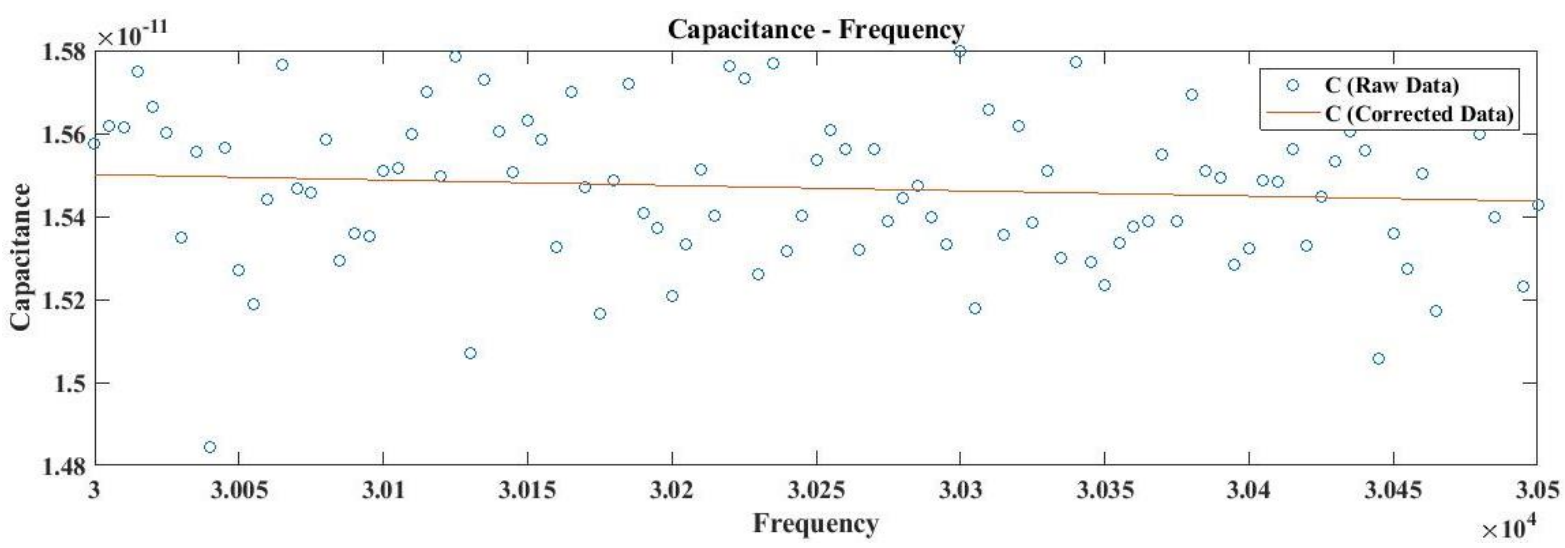

Figure 7 (e). Graph of Oven Dried Paddy 


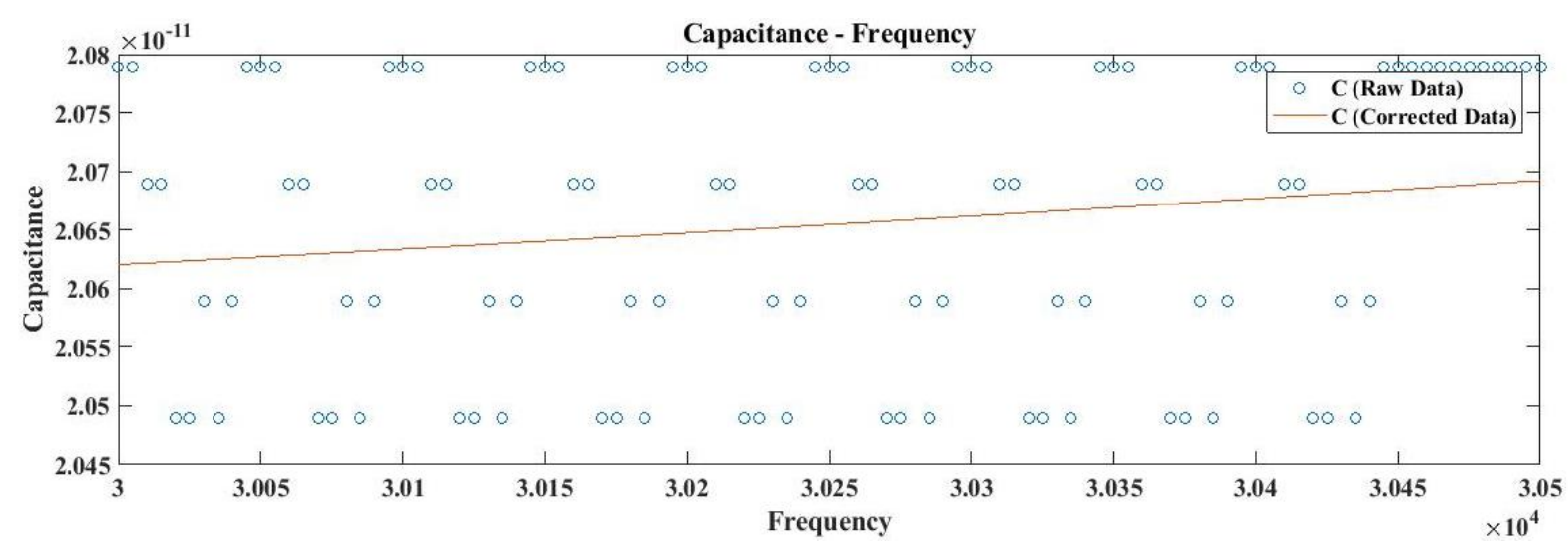

Figure 7 (f). Graph of Sun Dried Paddy

Figure 7. Frequency Versus Different Capacitor Values and its Corrected Data. (a) Graph of $10 \mathrm{pF}$ Capacitor (b) Graph of 22 pF Capacitor, (c) Graph of 27 pF Capacitor, (d) Graph of Moist Paddy, (e) Graph of Oven Dried Paddy, $(f)$ Graph of Sun Dried Paddy

The programming in Matlab was done to high light the data obtained using the circuit and to do corrections to avoid small error present in the readings. The blue bubbles of each graph are raw data or readings obtained from the designed circuit. There are hundred readings obtained from the circuit. The red line indicate the corrected value.

\section{DISCUSSION / CONCLUSIONS}

The present climatic conditions of our country are unpredictable and are unfavorable for the cultivation of paddy due to global warming. Paddy has to be stored for long time for future use and trading. So it became necessary that $\mathrm{MC}$ of grains have to measure frequently. The humidity and temperature also plays an important role in the variation of MC. The preservation of paddy is very critical as the moisture present in it encourages fungi growth. When the grains have to be preserved for long time, moisture content of grains is an important factor to be considered. New and better technique using the designed integrated circuit which has been developed gives promising result for the measurement of moisture in paddy. The capacitance readings obtained using the designed circuit was almost constant and the small error in pico farads are corrected using Matlab programming. With the readings obtained from the circuit, \% $\mathrm{MC}$ using the formula (8) was calculated. The technique can be used by any person and moisture content can be measured easily. The technique is accurate, simple and requires less time and it is more economy. The implementation cost is also affordable by the common farmers.

\section{CONFLICTS OF INTEREST}

No conflict of interest was declared by the authors.

\section{REFERENCES}

[1] Chari, V. K., and Nelson, S. O., "RF impedance method for estimating moisture content in small samples of in-shell peanuts", IEEE Transaction on Instrumentation and Measurement, 56(3): 938-942, (2007).

[2] Chari, V. K., Butts., C. L., and Nelson., S. O., "Capacitance sensor for non-destructive measurement of moisture content in nuts and grain", IEEE Transaction on Instrumentation and Measurement, 56(5): 1809-1813, (2007). 
[3] Chari, V. Kandala., and Jaya, Sundaram., "Nondestructive measurement of moisture content using a parallel plate capacitance sensor for nuts and grain", IEEE Sensors Journal, 10(7): 1282-1287, (2010).

[4] Nelson, S.O., "Dielectric properties of agricultural products-measurements and applications". IEEE transactions on Electrical Insulation, 26(5): 845-869, (1991).

[5] Nelsont, S.O., "Use of electrical properties for grain-moisture measurement", Journal of Microwave Power, 12(1): 67-72, (1977).

[6] Nelson, S.O., Kraszewski, A.W., Trabelsi, S., and Lawrence, K.C., "Using cereal grain permittivity for sensing moisture content", IEEE transactions on instrumentation and measurement, 49(3): 470475, (2000).

[7] Briggs, G., "An electrical resistance method for the rapid determination of the moisture content of grain," American Association for the Advancement of Science, 28(727): 810-813, (1908).

[8] Jishun, Jiang., and HuaJi., "Modeling of moisture test for grain based on neural network and dielectric loss factor", IEEE Computer Society, Second International Symposium, on Computational Intelligence and Design, 424 - 428, (2009).

[9] Ki-Bok, Kim., Jong -Heon, Kim., Seung, Seok, Lee., and Sang, Ha, Noh., "Measurement of grain moisture content using microwave attenuation at $10.5 \mathrm{GHz}$ and moisture density", IEEE Transaction on Instrumentation and Measurement, 51(1): 72-77, (2002).

[10] Nelson, S.O., and Bartley, P.G., "Measuring frequency-and temperature-dependent permittivities of food materials", IEEE Transactions on İnstrumentation and Measurement, 51(4): 589-592, (2002).

[11] Nelson, S. O., "Agriculture application of dielectric measurements", IEEE Transaction on Instrumentation and Measurement, 51(4): 688-702, (2005).

[12] Tripathi, R. K., Gupta, M,. and Shukla, J. P., "Capacitance technique for measuring moisture content using dielectric data- an immersion method", ICDL International conference on conduction and breakdown in dielectric liquids, 440-442, (1996).

[13] Mizukami, Y., Sawai, Y., and Yamaguchi, Y., "Moisture content of tea leaves by electrical impedance and capacitance", Biosystems Engineering, 93(3): 293-299, (2006).

[14] Tsukada, K., and Kiwa, T., "Magnetic measurement of moisture content of grain", IEEE Transaction on Magnetics, 43(6): 2683-2685, (2007).

[15] Chari, V. K., "Moisture Determination in Single Peanut Pods By Complex RF Impedance Measurement", IEEE Transaction on Instrumentation and Measurement, 53(6): 1493-1496, (2004).

[16] Kandala, C. V., and Puppala, N., "Capacitance sensors for nondestructive moisture determination in grain, nuts and bio-fuel materials", ICST., U S A., 42-45, (2012).

[17] Kandala, C. V., and Puppala, N., "Parallel plate capacitance sensors for nondestructive moisture content of different types of wheat", Sensors Application Symposium IEEE Bresua, 1-5, (2012).

[18] Kandala, C. V., Avula, R., Settaluri, V., Reddy, R.S. and Puppala, N., "Sensing the moisture content of dry cherries - A rapid and non-destructive method", Scientific Research, Food and Nutrition Sciences, 4, 38-42, (2013).

[19] "Moisture Measurement-Peanuts," American Society of Agricultural Engineers, St. Joseph, MI, ASAE S410.1, ASAE Standard, (2000). 
[20] Sellaluri, V. S., Kandala, C. V., Puppala, N. and Sundaram, J., "Peanuts and their nutritional aspectsA review", Food and Nutrition Sciences, 3: 1644-1650, (2012).

[21] Kandala, C. V., Rao, C. N., Rachaputi and Connor, D. O., "Capacitance Sensor for nondestructive determination of total oil content in peanut kernels" International Conference on Educational and Information Technology (ICEIT 2010) Scientific Research Journal of Sensor Technology, 3(1): 4246, (2013).

[22] Divya, Nath. K., Sudha, Ramasamy., Saranya Das, Y.M., Prabhu, Ramanathan., "A review on nondestructive methods for the measurement of moisture contents in food items", presented in Circuit, Power and Computing Technologies (ICCPCT), 2015 International Conference, IEEE Digital library,1-6, (2015).

[23] Saranya Das, Y. M., Divya, Nath. K., Ramaswamy, S., \& Ramanathan, P., "A review on sensor based methods for moisture content determination of agricultural commodities", International Journal of Applied Engineering Research, 10(2): 1697-1703, (2015).

[24] Divya, Nath. K., Ramanathan, P., "Non-destructive methods for the measurement of moisture contents - a review", Sensor Review, 37(1): 71-77, (2017). 